\title{
Incorporation of Short Chain Alkylamine in Template Micelle during MCM-41 Formation Process
}

\author{
Hyoung-Ho Lee ${ }^{1, *}$, Junji Shibata ${ }^{1}, \mathrm{Ji}-$ Whan $\mathrm{Ahn}^{2}$ and Hwan $\mathrm{Kim}^{3}$ \\ ${ }^{1}$ Department of Chemical Engineering, Kansai University, Osaka 564-8680, Japan \\ ${ }^{2}$ Institute of Geoscience \& Mineral Resources, Taejon 305-350, Korea \\ ${ }^{3}$ School of Materials Science and Engineering, Seoul National University, Seoul 151-742, Korea
}

\begin{abstract}
In our previous report, ethylamine was confirmed to have an affirmative effect on the improvement of structural stability of MCM-41 mesostructure. It was also found that the addition of ethylamine causes structural changes. This report presents an in-depth study on the effect of alkylamine with a short alkyl chain by analyzing produced mesoporous structures. It is found that ethylamine dissolves into cetyltrimethylammoniumbromide (CTAB) micelles when it is added together with ethanol. Several different short chain alkylamines were also examined without adding ethanol. With an increase in the hydrophobic chain length, indications of amine participation as a cosurfactant are intensified. The amine species participating in the templating process is identified to be neutral. The amines conditioned in a $\mathrm{pH}$ range above $p K_{\mathrm{a}}$ are found to strongly affect pore-to-pore distance and textural mesoporosity by dissolving themselves in micelles. Effect of short chain alkylamine is discussed with considerations of energy changes associated with micelle formation. [doi:10.2320/matertrans.M-MRA2007889]
\end{abstract}

(Received November 20, 2006; Accepted November 27, 2007; Published February 6, 2008)

Keywords: mesoporous, mobile's composition of matter (MCM)-41, alkylamine, cosurfactant

\section{Introduction}

Since MCM-41 was discovered by the scientists at Mobil Oil Co. in 1992, ${ }^{1,2)}$ various kinds of mesoporous silicates such as HMS, ${ }^{3)}$ MSU, ${ }^{4)}$ SBA-15 ${ }^{5)}$ and KIT-1 ${ }^{6}$ ) have been synthesized. These materials have attracted much attention from catalytic or adsorption industries dealing with bulky molecules because of their large pores (larger than $2 \mathrm{~nm}$ ) and well-ordered pore channels. Poor structural stability of mesoporous silicate is the most crucial weakness which hinders its industrial applications. Various efforts have been made to settle the problem. ${ }^{7-16)}$ Modifications in the process to improve stability, however, may result in changes in mesostructure, which are often overlooked. Catalytic activity is greatly dependent not only on the stability but also on the mesostructure. The applicability of mesoporous silicate as a catalyst can be determined only after comprehensive investigation of structural factors such as pore size and textural mesoporosity as well as structural stability.

In our previous report, ${ }^{17)}$ ethylamine (EA) was used to synthesize MCM-41 molecular sieves with high structural stability and long range order. Small angle X-ray scattering (SAXS) showed that the EA/CTAB ratio is the critical factor that determines the degree of ordering in MCM-41. The products have walls approximately $2 \mathrm{~nm}$ thick, and consequently they do not lose their structure even after heat treatment at $1000^{\circ} \mathrm{C}$. Some indications are found that added ethylamine takes part in the micelle-forming process to influence the final structure of mesoporous materials. This implies that the enhancement of structural stability by the addition of ethylamine is accompanied by changes in mesostructure.

In this report, more detailed study on the incorporation of alkylamine with short alkyl chain into a micelle is presented. The purpose of the study is to understand the interaction

*Post doctoral researcher, Kansai University between silicate precursor and incorporated alkylamine in order to get the control of both the structural stability and mesoporosity.

\section{Experimental}

\subsection{Synthesis}

The experiments performed can be divided into two parts. In the first part, the amounts of EA or ethanol (EtOH) were subject to variation, while the $\mathrm{CTAB} / \mathrm{Si}$ was fixed. The composition of synthesis mixture had the following molar ratio;

$$
\begin{gathered}
1 \mathrm{Si}-x \text { EA-0.5CTAB- } 100 \mathrm{H}_{2} \mathrm{O}-y \mathrm{EtOH} \\
(x=0.2,0.5,1,2 ; y=0,1,2,4)
\end{gathered}
$$

Tetraethylorthosilicate (TEOS), CTAB and EA were obtained from Aldrich. Ethanol was obtained from Haymann. All chemicals were reagent grade and used without further purification. Initially, solution 1 containing $\mathrm{H}_{2} \mathrm{O}, \mathrm{CTAB}$ and EA, and solution 2 containing ethanol and TEOS, were mixed for 30 minutes individually, and then solution 2 was added to solution 1 dropwise for a period of 10 minutes. The resultant solution was further stirred for 2 hours at a room temperature. Then the solution was transferred to a $250 \mathrm{~cm}$ Teflon bottle with a sealing cap and left in an oil bath filled with silicon oil at $100^{\circ} \mathrm{C}$ for 1 day. The product was filtered and washed twice with plenty of deionized water, dried in an oven at $80^{\circ} \mathrm{C}$ overnight, and calcined at $550^{\circ} \mathrm{C}$ for 6 hours to remove the remaining surfactant.

In the second part, several short-chain alkylamines were used in the process without the addition of ethanol. Ethylamine (EA, $C=2$ ), propylamine (PA, $C=3$ ) and butylamine (BA, $C=4)$ were adopted using the products of Aldrich. The amounts of these alkylamines were varied and again the $\mathrm{CTAB} / \mathrm{Si}$ was fixed. The composition of synthesis mixture had the following molar ratio; 
1Si- $x$ AA-0.5CTAB- $100 \mathrm{H}_{2} \mathrm{O}(x=0.2,0.5,1,2)$

The synthesis process other than the exclusion of ethanol was the same as described above.

\subsection{Characterization}

The microstructure images of the product were obtained with a high resolution TEM (Jeol JEM-3000F) operated at an acceleration voltage of $300 \mathrm{kV}$ and SEM (Jeol JSM-6330F) at $15 \mathrm{kV}$. Small-angle X-ray scattering (SAXS) data were collected on a Bruker GADDS diffraction system with a general area detector at $40 \mathrm{kV}$ and $30 \mathrm{~mA}$ with $\mathrm{Cu}-\mathrm{K} \alpha$ radiations $(\lambda=0.15418 \mathrm{~nm})$. The $\mathrm{N}_{2}$ adsorption-desorption isotherms were obtained using Micromeritics ASAP 2010. The samples were degassed in a vacuum at $200^{\circ} \mathrm{C}$ for more than 5 hours before measurements to evacuate the physisorbed moisture.

\section{Results and Discussion}

\subsection{Effect of ethanol}

Generally, ethanol is added in order to induce homogeneous synthesis reaction by diluting TEOS and relaxing the local concentration increase. Heating at $80^{\circ} \mathrm{C}$ during gelation is carried out, which would vaporize ethanol to prevent any morphological change derived from the existence of ethanol. As a preliminary experiment to investigate the influence of ethanol on the synthesis process, three variations were made in the systhesis condition, which are the addition of ethanol and heating at $80^{\circ} \mathrm{C}$, no ethanol and heating at $80^{\circ} \mathrm{C}$, and no ethanol and no heating. $\mathrm{CTAB} / \mathrm{Si}$ mole fraction was fixed to 0.5 , and $\mathrm{EA} / \mathrm{Si}$ was varied to be $0.2,0.5,1$ and 2 , in any cases. Figure 1 shows the SAXS patterns of the products. It is found that the interplanar spacings in the SAXS patterns are greatly influenced by ethanol. Heating during gelation does not make any difference in the spacings, and synthesis with room temperature reflux produces well-ordered nanostructure. Based on this result, alcohol additions of different amounts at a room temperature with $\mathrm{EA} / \mathrm{Si}$ and $\mathrm{CTAB} / \mathrm{Si}$ mole fractions fixed as the above are discussed using the SAXS results in our previous report. ${ }^{17)}$

Figure 2(a) and (b) shows the SEM images of the products with $\mathrm{EA} / \mathrm{Si}=0.2$ and $\mathrm{EA} / \mathrm{Si}=1$, respectively. Ethanol was not added in both cases. The well-ordered channels observed in the latter are in sharp contrast to the agglomerated structure in the former. Figure 2(c) and (d) present SEM images of the products synthesized in the presence of ethanol. It is found in Fig. 2 that ethanol induces more complicated morphology. The evolution of textural porosity with an increase in ethanol amount can be identified from the series of the SEM images. Alignment between channels becomes irregular with the addition of ethanol. In our previous report, ${ }^{17)}$ same tendency was found with an increase in ethylamine amount in the $\mathrm{N}_{2}$ adsorption-desorption curves. The effect of ethanol on a decrease in interplanar spacings and channel ordering is again confirmed in the SAXS patterns in Fig. 3. Part of the patterns is from the previous report. ${ }^{17)}$ Ethylamine seems to incorporate in a micelle as a cosurfactant only in the presense of ethanol. There are two possible ways that small amphiphilic molecules like short alkyl chain

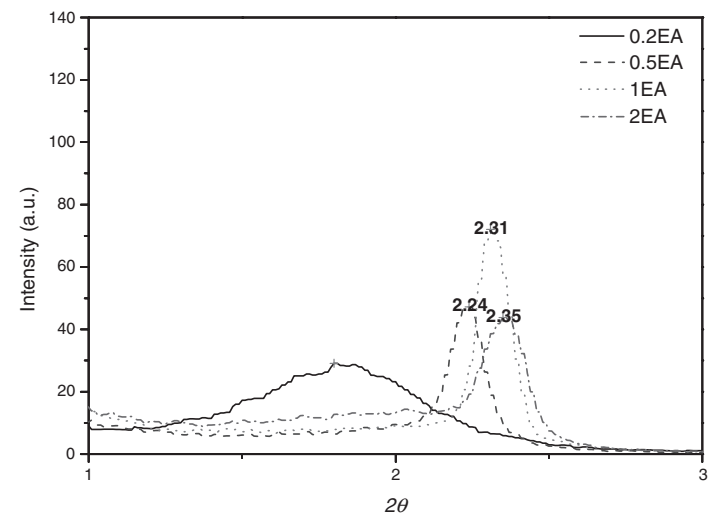

(a)

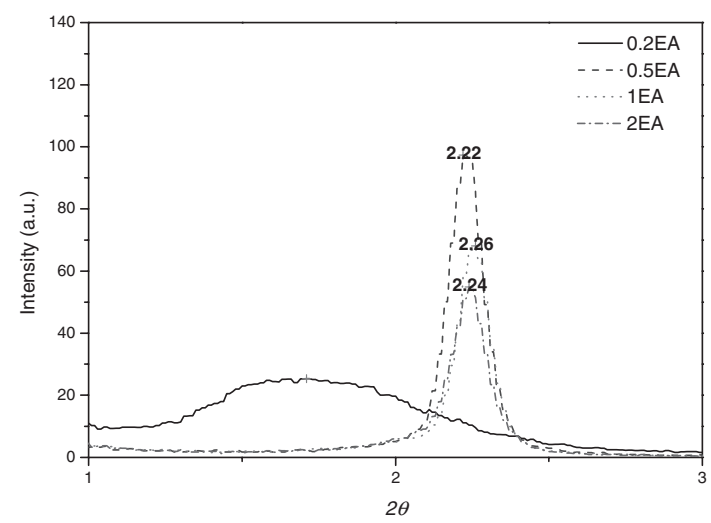

(b)

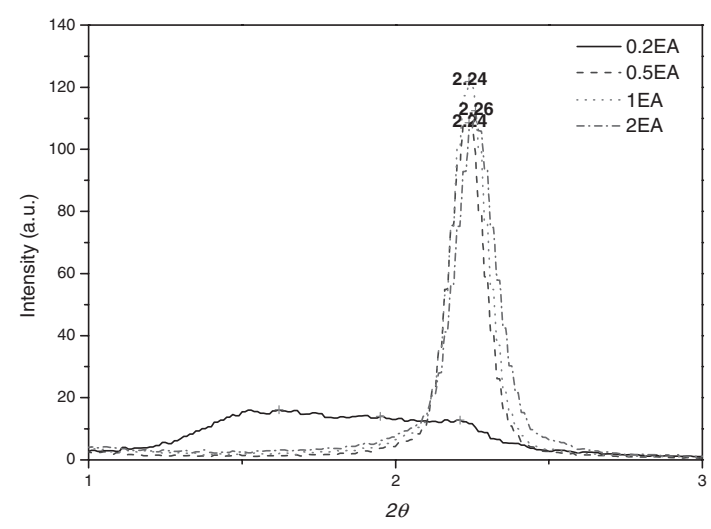

(c)

Fig. 1 SAXS results for products synthesized in conditions of (a) $80^{\circ} \mathrm{C}$ heating during hydrolysis in the presence of ethanol, (b) $80^{\circ} \mathrm{C}$ heating during hydrolysis in the absence of ethanol, and (c) no heating during hydrolysis in the absence of ethanol.

amines dissolve themselves in a micelle when they are added to a surfactant solution. The one is a cosurfactant ${ }^{18,19)}$ and the other is a swelling agent, ${ }^{20)}$ as described in Fig. 4. In the case of a cosurfactant, micelle contracts because these small substitutes loosen crowded core part of the micelle. In the case of a swelling agent, however, the diameter of micelle increases because the amphiphilic molecules dissolved into the core part of the micelle swell the micelle.

The textural porosity and loss of long-range order are thought to result from the neutral interaction between inorganic precursor and alkyl chain amine. Because neutral interaction is not as strong as the electrostatic interaction, 


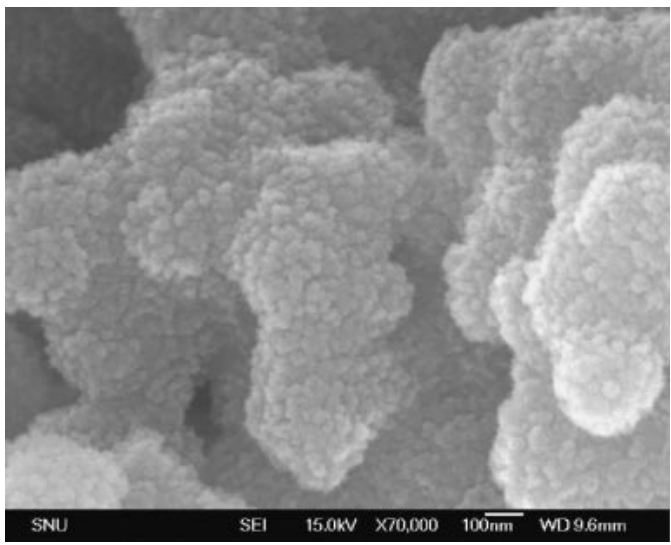

(a)

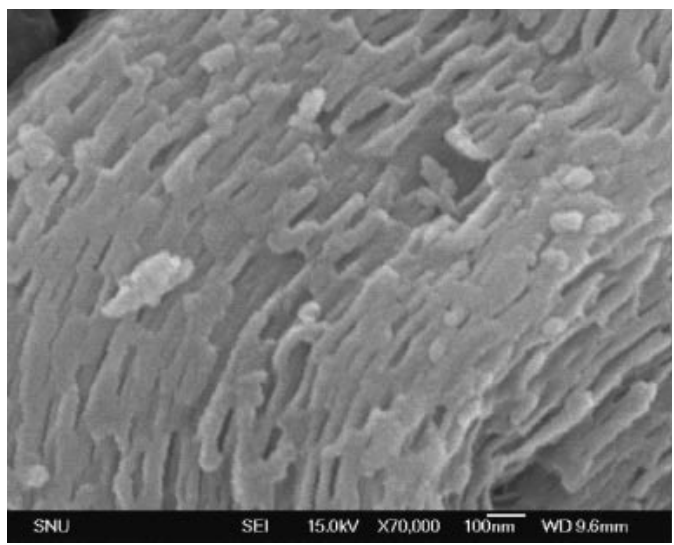

(c)

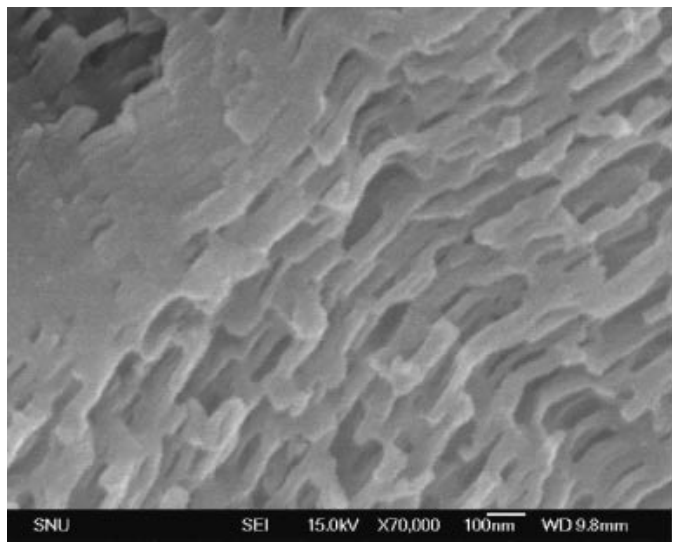

(b)

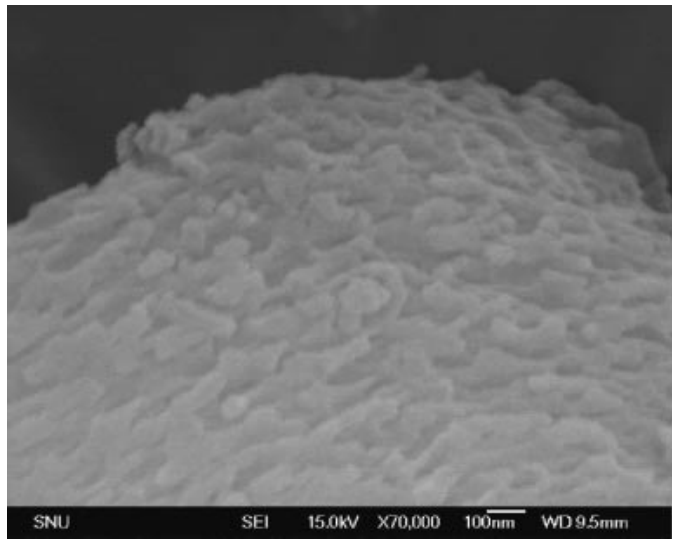

(d)

Fig. 2 Scanning electron micrographs (SEM) of samples synthesized in the condition of (a) EA/Si $=0.2$ and EtOH/Si $=0,(b) \mathrm{EA} /$ $\mathrm{Si}=1$ and $\mathrm{EtOH} / \mathrm{Si}=0,(\mathrm{c}) \mathrm{EA} / \mathrm{Si}=1$ and $\mathrm{EtOH} / \mathrm{Si}=1$ and $(\mathrm{d}) \mathrm{EA} / \mathrm{Si}=1$ and $\mathrm{EtOH} / \mathrm{Si}=4$.

their compelling force to align the channels is weak. Neutral characteristic of interaction is also verified by the plots in Fig. 5, which is produced by reconstructing Fig. 3 for the same amount of ethylamine, 0.5EA/Si and 1EA/Si. A decrease in interplanar spacings and gradual disordering with an increase in ethanol amount are found in the patterns of 1EA/Si series, while interplanar spacings do not change in the patterns of $0.5 \mathrm{EA} / \mathrm{Si}$ series. Main difference between 1EA/Si and 0.5EA/Si series is surface charge state of amine. Figure 6 shows $\mathrm{pH}$ profile of synthesis mixture during the initial stage of synthesis. Micelle formation is known to be completed in the initial several minutes. Ethylamine is situated at a $\mathrm{pH}$ slightly under its $p K_{\mathrm{a}}=10.64$ during the period for the $0.5 \mathrm{EA} / \mathrm{Si}$ solution, and it is at a $\mathrm{pH}$ over the $p K_{\mathrm{a}}$ for the $1 \mathrm{EA} / \mathrm{Si}$. If the measured $\mathrm{pH}$ value is approximated as $-\log \left[\mathrm{H}^{+}\right]$by assuming ideal solution and constant activity coefficient of proton, it is supposed that the concentration of neutral species is the same as that of the positively charged one at the $\mathrm{pH}$ of $p K_{\mathrm{a}}$, according to the following equation defining $p K_{\mathrm{a}}$;

$$
\mathrm{RNH}_{3}{ }^{+} \leftrightarrows \mathrm{RNH}_{2}+\mathrm{H}^{+}
$$

where $R$ means alkylchain, $\mathrm{C}_{\mathrm{n}} \mathrm{H}_{2 \mathrm{n}+1}$.

$$
K_{\mathrm{a}}=\frac{\left[R N H_{2}\right]\left[\mathrm{H}^{+}\right]}{\left[\mathrm{RNH}_{3}{ }^{+}\right]}=10^{-10.64}
$$

where square brackets are used to denote the concentration of species.

If we take logarithms on both sides of the above equation, it becomes as follows;

$$
\mathrm{pH}=\log \frac{\left[R N H_{2}\right]}{\left[R^{2} H_{3}{ }^{+}\right]}+p K_{\mathrm{a}}=\log \frac{\left[R N H_{2}\right]}{\left[R_{N} H_{3}{ }^{+}\right]}+10.64
$$

At $\mathrm{pH}$ of $p K_{\mathrm{a}}$, equation (1) produces the following concentration ratio for $\mathrm{EA} / \mathrm{Si}=0.5$;

$$
\frac{\left[\mathrm{RNH}_{2}\right]}{\left[\mathrm{RNH}_{3}{ }^{+}\right]} \fallingdotseq 1 \quad(\text { for } \mathrm{EA} / \mathrm{Si}=0.5)
$$

It is possible to calculate the ratio of neutral species and protonated ones for $\mathrm{EA} / \mathrm{Si}=1$ using the corresponding $\mathrm{pH}$ value of about 11 found in Fig. 6;

$$
\frac{\left[\mathrm{RNH}_{2}\right]}{\left[\mathrm{RNH}_{3}{ }^{+}\right]} \fallingdotseq 2.3 \quad(\text { for } \mathrm{EA} / \mathrm{Si}=1)
$$

Alkylamine exists mainly as a neutral species in the 1EA/Si mixture, but the neutral species do not dominate in $0.5 \mathrm{EA} / \mathrm{Si}$ mixture. Figure 5 verifies the neutral state of alkylamine species joining in a micelle. In other words, ethylamine only existing in neutral form seems to participate in a micelle as a corsufactant.

There remains a question why this occurs only with the addition of ethanol. Alcohols and amines are known to form 


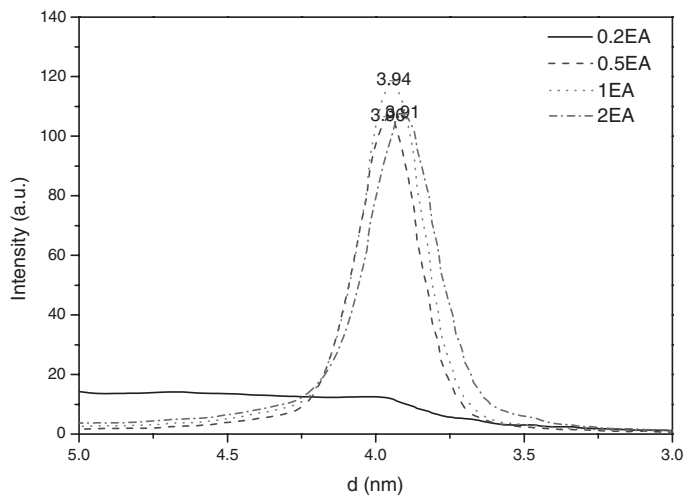

(a)

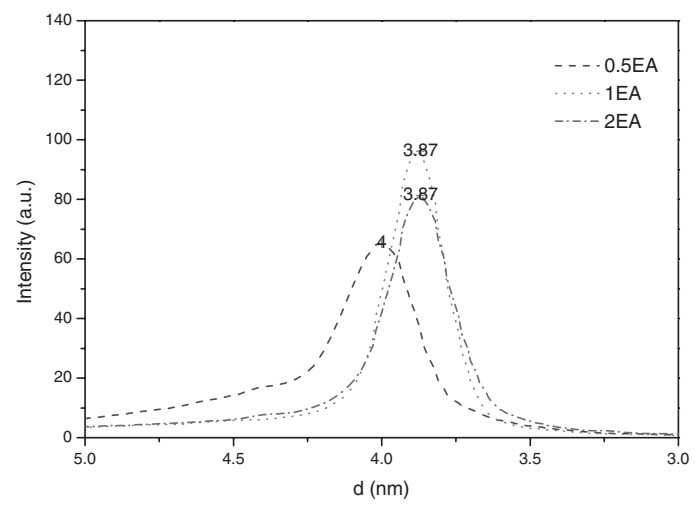

(c)

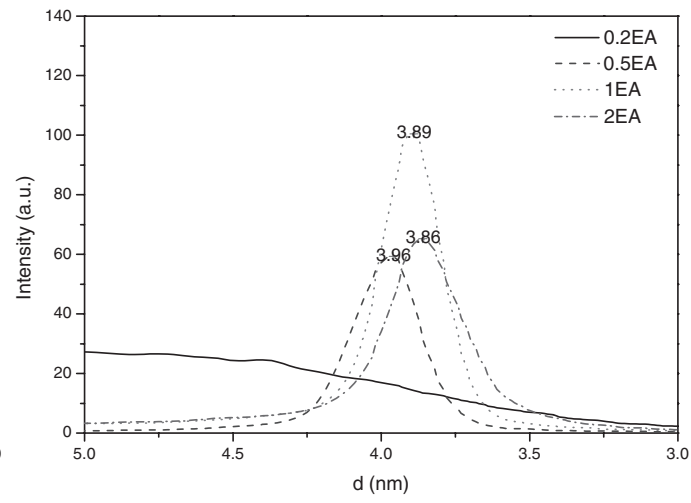

(b)

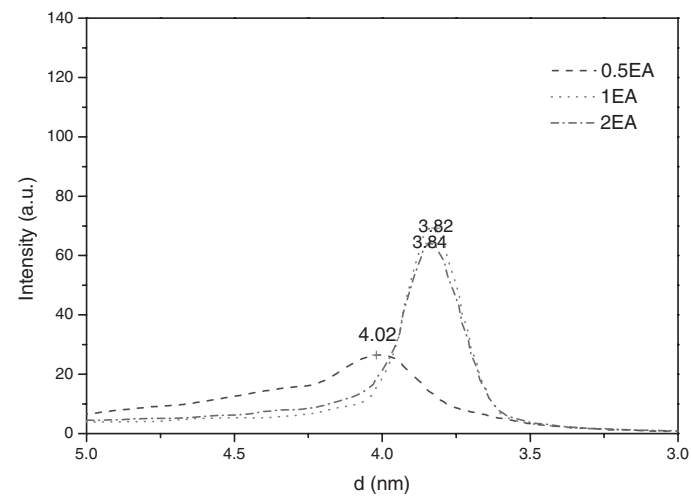

(d)

Fig. 3 SAXS patterns of products obtained from initial mixtures of various EA and ethanol concentrations in case of ethanol/Si ratios of (a) 0 , (b) 1 , (c) 2 and (d) 4 .
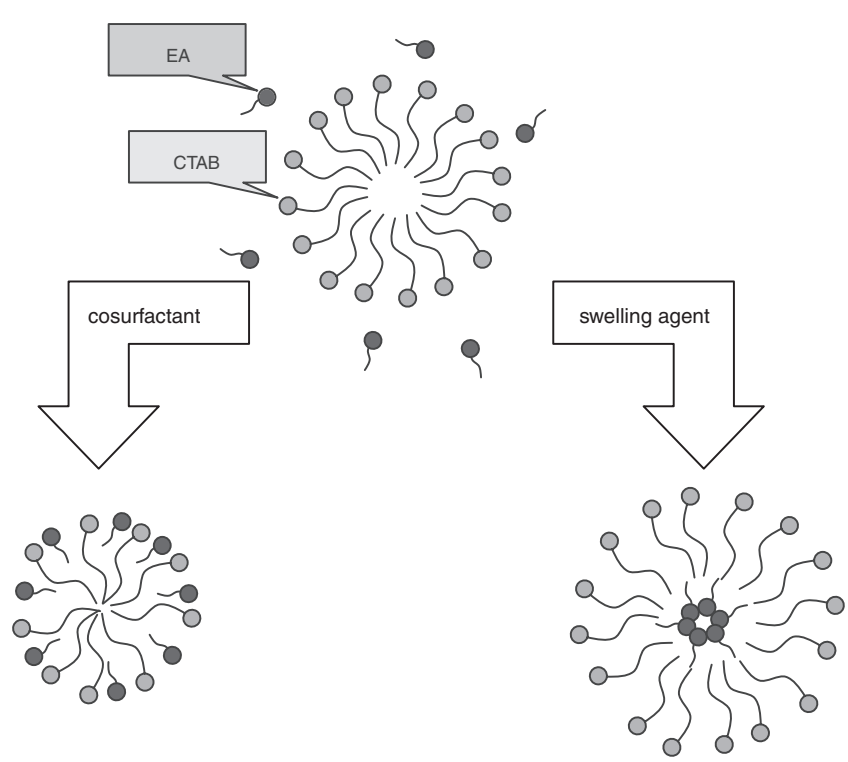

Fig. 4 Schematic representation for change in micelle configuration due to incorporation as a swelling agent or a cosurfactant.

strong hydrogen bonds exhibiting the large negative excess enthalpies. $^{21)}$ As an immediate example, surfactant amine is removed by extraction with alcohol in the synthesis process of HMS mesoporous materials. ${ }^{3)}$ The decisive clues are found in the modified flotation technique in mineral processing, in which amines are used to collect silicates in cooperation with alcohol. $^{22-24)}$ Amines adsorbed onto silicate surface yield a formation of 2D aggregates which is called hemi-micelle, at a certatin critical value of amine concentration. Silicates with this hydrophobic coating are collected easily because of spontaneous floating. In the presence of alcohols, the hemimicelle phenomenon takes place at smaller concentrations of amine, because alcohol forms complex with amine, then substantially increasing the hydrophobicity of hydrocarbon groups without changing the state of head parts considerably. This amine-alcohol complex with increased hydrophobicity incorporate in a micelle more easily.

\subsection{Energetic consideration concerning cosurfactant incorporation}

Energy change associated with micelle formation is thought to be mainly composed of three components. The one is related to the interaction between the head groups of surfactants in a micelle and the other two are related to the interactions between the tail groups of surfactants. Head group interaction is mainly electrostatic repulsion between charged units of the cationic surfactants such as CTAB, which is generally used in the synthesis of M41S. Energy change resulting from electrostatic repulsion between head groups, $\Delta G_{\mathrm{h}}$, is an obstacle to micelle formation. The tail groups experience both the hydrophobic (van der Waals) attraction and steric repulsion between them. They are designated as $\Delta G_{\mathrm{t} 1}$ and $\Delta G_{\mathrm{t} 2}$, respectively. Interactions are simplified in this discussion by assuming that the three 


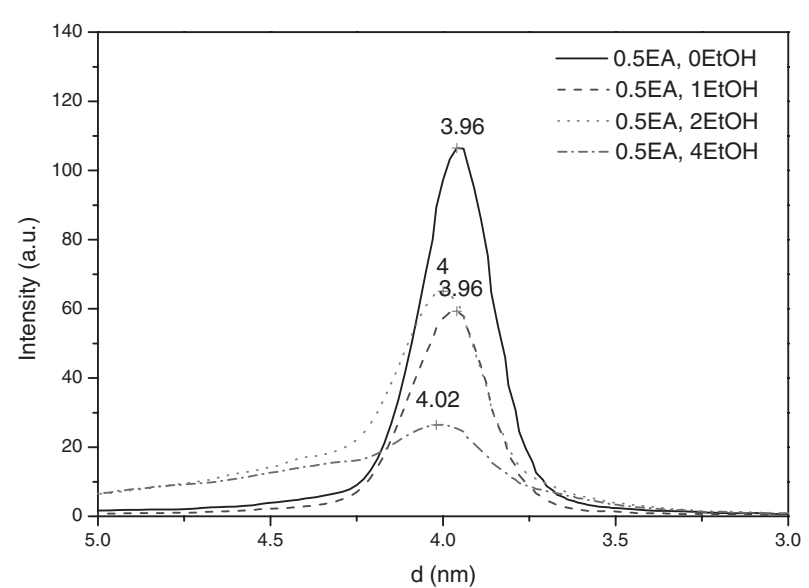

(a)

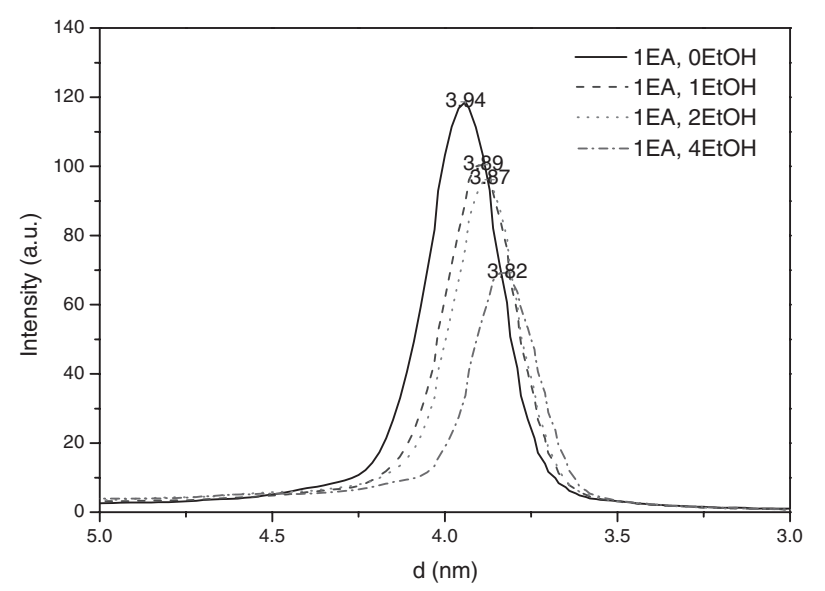

(b)

Fig. 5 SAXS patterns of products obtained from mixtures of various EA and ethanol concentrations in case of EA/Si ratios of (a) 0.5 and (b) 1.

energy components are independent from each other and other minor factors such as interaction between head groups and tail groups are ignorable. The following general equation is established;

$$
\Delta G_{\mathrm{m}}=\Delta G_{\mathrm{h}}+\Delta G_{\mathrm{t} 1}+\Delta G_{\mathrm{t} 2}
$$

$\Delta G_{\mathrm{m}}$ : Gibbs free energy change of micelle formation

$\Delta G_{\mathrm{h}}$ : Energy change resulting from electrostatic repulsion between head groups

$\Delta G_{\mathrm{t} 1}$ : Energy change resulting from hydrophobic attraction between tail groups

$\Delta G_{\mathrm{t} 2}$ : Energy change resulting from steric hindrance between tail groups

The driving force to form a micelle is based on $\Delta G_{\mathrm{t} 1}$. In other words, a micelle is formed to hide the hydrophobic parts from the hydrophilic media. Hydrophobicity of tail parts should exceed a critical point for micelle formation to take place, because there are always resisting forces based on $\Delta G_{\mathrm{t} 2}$ and $\Delta G_{\mathrm{h}} . \Delta G_{\mathrm{t} 1}$ has a negative value, while $\Delta G_{\mathrm{t} 2}$ and $\Delta G_{\mathrm{h}}$ are positive, in a conventional way. When small alkylamine molecules replace $\mathrm{CTAB}$, changes occur in the conformation of the surfactants constituting a micelle. Both the hydrophobic attraction and steric hindrance between tail groups decrease with the replacement; the absolute values of $\Delta G_{\mathrm{t} 1}$ and $\Delta G_{\mathrm{t} 2}$ decrease. In general, $\Delta G_{\mathrm{t} 1}$ is larger than $\Delta G_{\mathrm{t} 2}$,

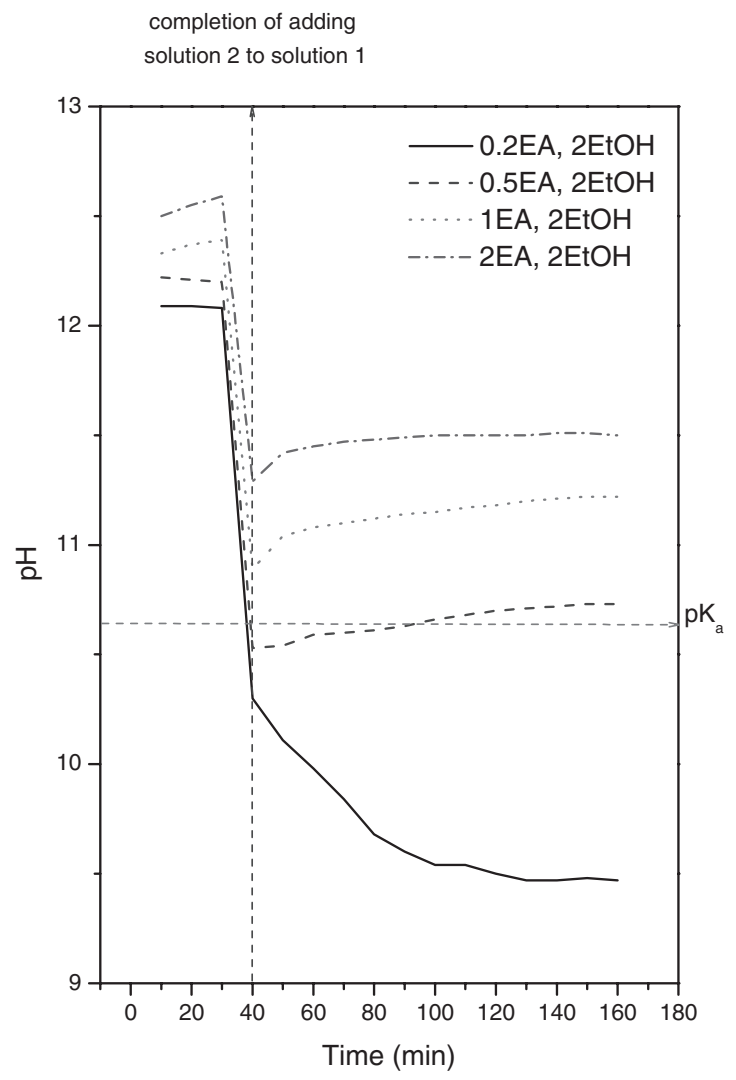

Fig. $6 \mathrm{pH}$ profile during initial mixing with ethanol $/ \mathrm{Si}=2$.

because the absolute value of $\Delta G_{\mathrm{t} 1}$ must be comparable to the sum of $\Delta G_{\mathrm{t} 2}$ and $\Delta G_{\mathrm{h}}$ in the equilibrium conformation. Therefore, when $\Delta G_{\mathrm{t} 1}$ and $\Delta G_{\mathrm{t} 2}$ are taken into account, the incorporation of ethylamine in the micelle in place of CTAB seems to be unfavorable. The less hydrophobic the added amines are, the less likely the replacement happens. It is suggested that this is why ethylamine could not function as a cosurfactant by itself unless ethylamine is mixed together with ethanol to make an amine-alcohol complex with increased hydrophobicity. The area occupied by protonated amine head group is smaller than that of CTAB. Surface charge density of protonated amine head group is larger than that of CTAB, in other words. The replacement of CTAB by pronated ethylamine will increase the electrostatic repulsion between head groups, $\Delta G_{\mathrm{h}}$, which implies that this is an unfavorable process. On the contrary, the replacement by neutral ethylamine will relax the electrostatic repulsion by screening the charges of CTAB and consequently decreasing $\Delta G_{\mathrm{h}}$. Unfavorable energy increase in $\Delta G_{\mathrm{t} 1}$ is dominated by $\Delta G_{\mathrm{h}}$ decrease in the case of replacement by neutral ethylamine. If the ethylamine is positively charged, then both the change in $\Delta G_{\mathrm{h}}$ and change in $\Delta G_{\mathrm{t} 1}$ are unfavorable for the participation of ethylamine in a micelle, and it will not happen.

\subsection{Effect of alkyl chain length}

The difference caused by alcohol is the increased hydrophobicity of amine tail group. Similar conditions without ethanol are established by adopting alkyl amines with longer chains. The same synthesis reaction without ethanol was carried out using ethylamine (EA, $C=2$ ), propylamine (PA, 


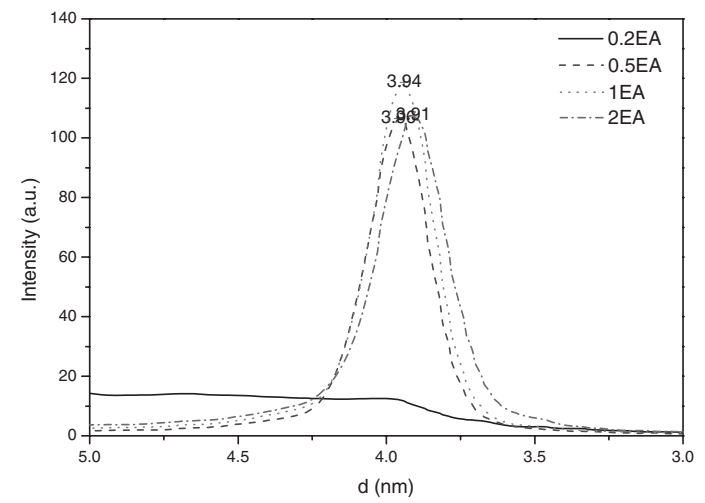

(a)

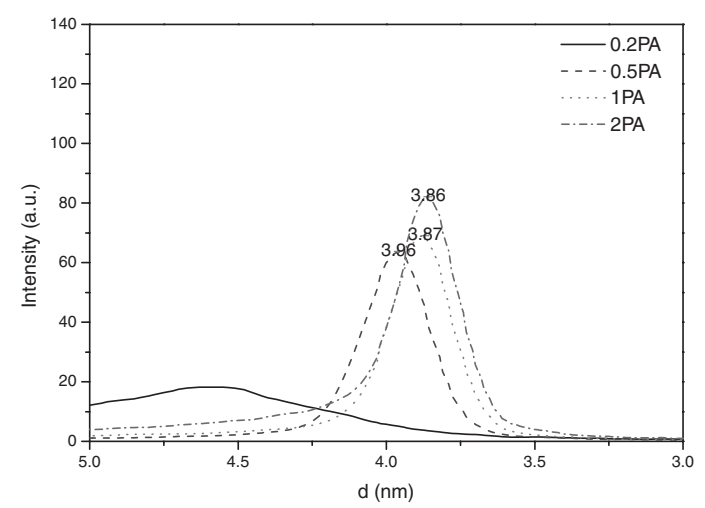

(b)

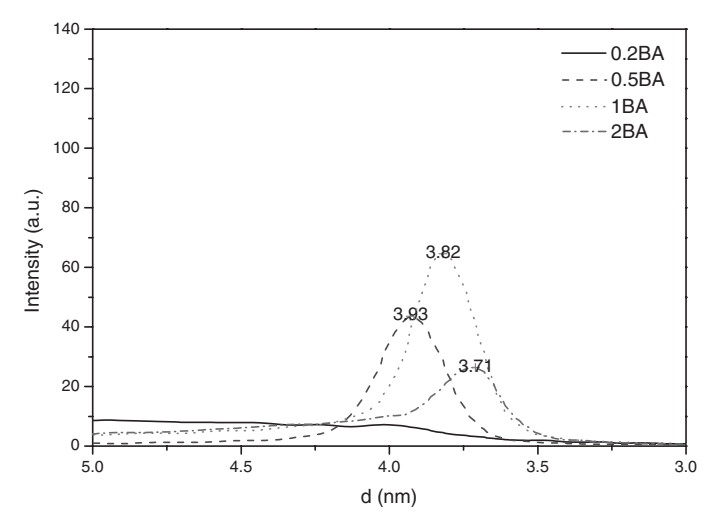

(c)

Fig. 7 SAXS patterns of products obtained with addition of various alkylamines, ethylamine, propylamine and butylamine.

$C=3$ ) and butylamine (BA, $C=4)$. Both the protonated and deprotonated forms of short chain alkylamines with $C=$ $1 \sim 6$ are known to be fully soluble in water. Figure 7 shows the SAXS patterns of the products. The similar tendency is verified as the results of ethanol-added process. Interplanar spacing does not change a lot with a change in the amount of ethylamine. However, interplanar spacing decreases with an increase in the amount of propylmaine and the degree of decrease becomes still greater with butylamine. The change from ethylamine to butylamine implies the decrease of difference between the hydrophobicity of CTAB chain and that of amine chain. Figure 8 presents SAXS patterns arranged in a different way using the results of Fig. 7. When conditioned at the $\mathrm{pH}$ above $p K_{\mathrm{a}}$, in which neutral amines predominate over positively charged ones, the interplanar

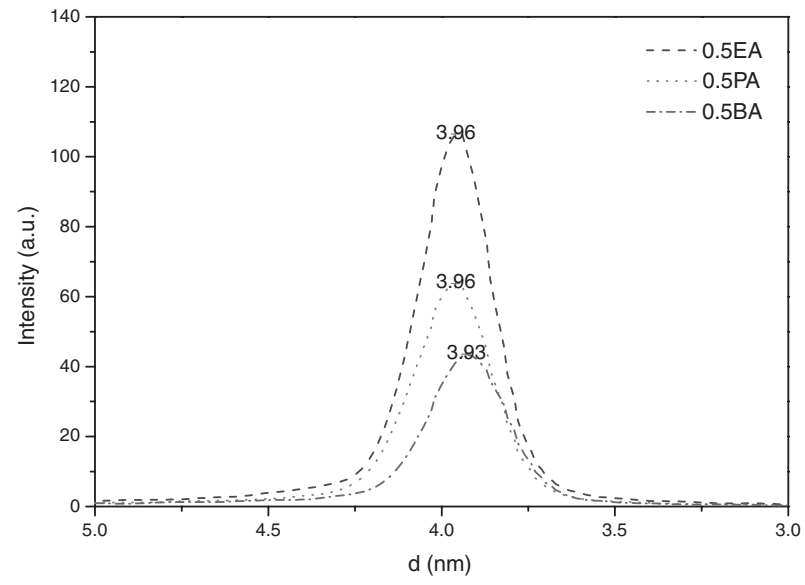

(a)

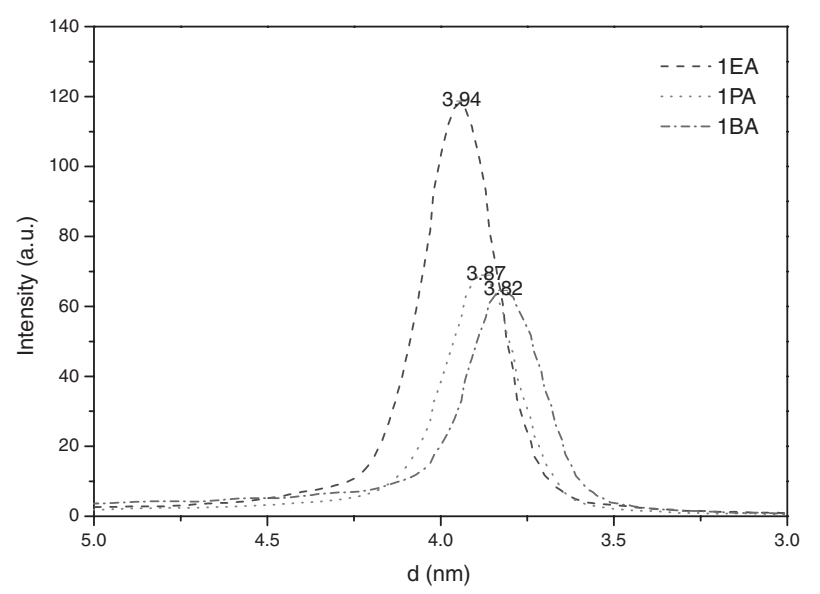

(b)

Fig. 8 SAXS patterns of products obtained with addition of alkylamines having different chain lengths in case of alkylamine/Si ratios of (a) 0.5 and (b) 1 .

spacings decrease with an increase in the chain length of alkylamines. This is not the case for the $\mathrm{pH}$ condition under $p K_{\mathrm{a}}$; the interplanar spacings do not change with a change in the chain length of alkylamines. It confirms again the decisive contributions of $\Delta G_{\mathrm{h}}$ and $\Delta G_{\mathrm{t} 1}$ towards the cosurfactant incorporation of alkylamine.

\section{Conclusions}

Ethylamine participates in a micelle as a cosurfactant only when ethanol coexists in a synthesis mixture. Interplanar spacings decrease with an increase in the amount of ethylamine in the presence of ethanol. The degree of decrease becomes larger with the amount of ethanol. It is suggested that ethylamine could incorporate in a micelle with increased hydrophobicity by combining with ethanol. This implies that the similar results may be obtained without adding ethanol by adopting alkylamines with longer alkyl chains. When alkylamines having $C=2 \sim 4$ are used, the expected results are obtained. While interplanar spacing does not change with an increase in the amount of ethylamine, it decreases with increasing the amount of propylamine, and the degree of decrease becomes greater with butylamine. When the alkylamine/ $\mathrm{Si}$ ratio is 0.5 , the increase in alcohol content or 
increased amine chain length do not affect the interplanar spacings, but the decrease in interplanar spacings is identified in the case of alkylamine/ $\mathrm{Si}=1$. The difference between these two is the charge of predominant amine species, which is positive for alkylamine/Si of 0.5 and neutral for 1 . Only neutral amine species seems to incorporate into a micelle. It can be properly explained by considering energy changes resulting from micelle formation. The species having neutral charge reduces the free energy of micelle formation to make the incorporation into micelle more probable. The model of energy consideration, however, needs further study because it is still too qualitative to clarify the process of micelle formation.

\section{Acknowledgements}

This work was supported by the Korea Research Foundation Grant. (KRF-M01-2005-000-10105-0)

\section{REFERENCES}

1) C. T. Kresge, M. E. Leonowicz, W. J. Roth, J. C. Vartuli and J. S. Beck: Nature 359 (1992) 710-712.

2) J. S. Beck, J. C. Vartuli, W. J. Roth, M. E. Leonowicz, C. T. Kresge, K. D. Schmitt, C. T.-W. Chu, D. H. Olson, E. W. Sheppard, S. B. McCullen, J. B. Higgins and J. L. Schlenker: J. Am. Chem. Soc. 114 (1992) 10834-10843.

3) P. T. Tanev and T. J. Pinnavaia: Science 267 (1995) 865-867.

4) S. A. Bagshaw, E. Prouzet and T. J. Pinnavaia: Science 269 (1995) 1242-1244.

5) D. Zhao, J. Feng, Q. Huo, N. Melosh, G. H. Fredrickson, B. F. Chmelka and G. D. Stucky: Science 279 (1998) 548-552.

6) R. Ryoo, J. M. Kim, C. H. Ko and C. H. Shin: J. Phys. Chem. 100 (1996) 17718-17721.

7) J. M. Kim, S. Jun and R. Ryoo: J. Phys. Chem. B103 (1999) 62006205.

8) Q. H. Xia, K. Hidajat and S. Kawi: Mater. Lett. 42 (2000) 102-107.

9) P. Van Der Voort, M. Baltes and E. F. Vansant: J. Phys. Chem. B103 (1999) 10102-10108.

10) R. Mokaya: J. Phys. Chem. B103 (1999) 10204-10208.

11) S. C. Shen and S. Kawi: J. Phys. Chem. B103 (1999) 8870-8876.

12) Y. Liu, W. Zhang and T. J. Pinnavaia: Angew. Chem. Int. Ed. 40 (2001) 1255-1258.

13) Z. Zhang, Y. Han, L. Zhu, R. Wang, Y. Yu, S. Qiu, D. Zhao and F. S. Xiao: Angew. Chem. Int. Ed. 40 (2001) 1258-1262.

14) Z. Zhang, Y. Han and F. S. Xiao: J. Am. Chem. Soc. 123 (2001) 50145021.

15) D. T. On and S. Kaliaguine: Angew. Chem. Int. Ed. 41 (2002) 10361040 .

16) W. Lin, Q. Cai, W. Pang, Y. Yue and B. Zou: Microporous Mesoporous Mater. 33 (1999) 187-196.

17) H. Lee, J. Ahn and H. Kim: Ceram. Int. 30 (2004) 817-822.

18) P. Agren, M. Linden, J. B. Rosenholm, R. Schwarzenbacher, M. Kriechbaum, H. Amenitsch, P. Laggner, J. Blanchard and F. Schuth: J. Phys. Chem. B103 (1999) 5943-5948.

19) P. Agren, M. Linden, J. B. Rosenholm, J. Blanchard, F. Schuth and H. Amenitsch: Langmuir 16 (2000) 8809-8813.

20) M. Kruk, M. Jaroniec and A. Sayari: Microporous Mesoporous Mater. 35-36 (2000) 545-553.

21) A. Heintz and D. Papaioannou: Thermochimica Acta 310 (1998) 6976.

22) A. Vidyadhar, K. Hanumantha Rao, I. V. Chernyshova, Pradip and K. S. E. Forssberg: J. Colloid Int. Sci. 256 (2002) 59-72.

23) A. Vidyadhar, K. Hanumantha Rao and I. V. Chernyshova: Physicochem. Eng. Aspects 214 (2003) 127-142.

24) M. B. N. Monte and J. F. Oliveira: Minerals Eng. 17 (2004) 425-430. 